\title{
LOGISTICS OUTSOURCING BY MANUFACTURERS IN SOUTH AFRICA
}

\author{
BEVERLEY WAUGH \\ ROSE LUKE \\ beverleyk@uj.ac.za \\ Department of Transport and Supply Chain Management \\ University of Johannesburg
}

\begin{abstract}
As organisations find themselves in an increasingly dynamic and competitive world they are seeking new strategies to ensure their competitive advantage and profitability. Logistics presents an area in which these organisations can improve customer service and reduce costs, and strategies in support thereof such as the outsourcing of logistics activities, should be considered. However, it is critical that logistics outsourcing is done diligently to avoid potential problems for the organisation and to achieve the best possible benefits. In South Africa little research has been done regarding current outsourcing practices of local manufacturers. In this article literature on international logistics outsourcing as well as research on some of the logistics outsourcing practices of South African manufacturers is discussed. The findings of a questionnaire survey of South African manufacturers provided information on their logistics outsourcing practices and problems. Prominent issues seem to include inadequate managerial involvement in the logistics outsourcing process, as well as insufficient time spent on many of the important aspects of the outsourcing agreement, the transitioning of resources and ongoing management of the outsourced relationship. It is concluded that a thorough outsourcing process should be followed in order to achieve the benefits of logistics outsourcing.
\end{abstract}

\section{INTRODUCTION}

It is risky for an organisation to hand over its very connectivity to its customers to an outside organisation. This is what organisations outsourcing logistics activities are doing. However, due to the fact that manufacturing organisations in South Africa are competing in an increasingly difficult market, many are indeed seeking to outsource their logistics activities to a third party logistics provider (3PL) (Kujawa, 2004). As with organisations world-wide, South Africans are under pressure from customers to increase customer service and decrease costs, but also from shareholders to increase market share and returns. Furthermore, South African organisations are geographically far removed from most of their international suppliers and customers, making their logistics more complex and costly. They are thus being forced to seek innovative ways in which to increase their competitive advantage and improve their profitability. However, although there are many 3PLs in South Africa and many 
manufacturers making use of 3PLs, little research has been done on the practices and issues of these parties (Kujawa, 2004).

The competitive manufacturing environment is one that is rapidly changing as globalisation and technology force organisations to constantly seek ongoing improvement in all areas in terms of their knowledge, flexibility and performance. Logistics, for example, is receiving growing attention as an area in which efficiency and productivity increases can be made in order to improve customer service and to lower costs (Stock \& Lambert, 2001). However, logistics is often not an area of core competence for many organisations. In order to compete successfully in the dynamic manufacturing environment, organisations are increasingly choosing to focus on their own area of competence and expertise, and to outsource their logistics requirements. If this logistics outsourcing is undertaken and managed well, it can hold many benefits for the organisation. Considering the above-mentioned pressures, it is relevant to investigate how South African organisations could outsource their logistics requirements in the most efficient manner with regard to customer service and cost.

In general, 'outsourcing can be described as the process of purchasing goods or services on specification, from an external supplier, that were previously produced in-house' (Mclvor, 2005 as quoted by Hugo \& Badenhorst-Weiss, 2011:62). Therefore, 'outsourcing can involve the transfer of an entire business function to a supplier. Alternatively, outsourcing may lead to the transfer of some activities associated with the function while some are kept in-house' (Hugo \& Badenhorst-Weiss, 2011:2). Logistics outsourcing is defined, for the purposes of this article, as the process whereby an organisation contracts a logistics service provider, i.e. a third party, with the necessary expertise, to perform recurring logistics activities that were, or could be, performed in-house in the short or long term, with risk, gain and information sharing. This process tends to involve long-term and expanded service offerings, with mutually beneficial and dependent relationships between the parties involved, often spanning multiple logistics processes (Lynch, 2000; Burns, Warren \& Cook, 2001; Ravi, 2001; Chow \& Gritta, 2002; Langley, Allen \& Tyndall, 2002; Hanna, 2009).

Research has shown that organisations with many years' experience in outsourcing know how to manage outsourcing arrangements to achieve well-defined business outcomes and achieve a high level of satisfaction with their outsourcing arrangements (Hanna, 2009). With regard to opinions and levels of success experienced with logistics outsourcing by manufacturers in South Africa, the limited research undertaken thus far showed that there do seem to be possible courses of action and areas of consideration necessary for the success of logistics outsourcing initiatives (Kujawa, 2004). The practices, processes and issues involved in logistics outsourcing should thus be identified, defined well and dealt with in order to avoid unnecessary mistakes and outsourcing failure and to ensure high levels of satisfaction (Greaver, 1999; Lynch, 2000). 
Should organisations make incorrect decisions regarding the outsourcing of their logistics, they risk compromising their customer loyalty, market and bottom line. Logistics outsourcing should thus be clearly understood as an important concept and key strategy with potentially far-reaching implications for any manufacturer. However, many organisations still outsource their logistics neglecting important aspects of the process. Much research has been done internationally on this topic but in South Africa specific research highlighting practices, and identifying recommendations, in these regards is lacking (Langley et al., 2002; Kujawa, 2004).

\section{Purpose of the article}

This article 1) discusses the practices identified in the literature related to the recommended logistics outsourcing process; 2 ) reports on the findings of research into logistics outsourcing practices of South African manufacturers; and 3) makes recommendations, based on the literature and survey, to manufacturers regarding logistics outsourcing.

\section{Theoretical background}

In the following subsections a theoretical foundation and conceptualisation of these logistics outsourcing practices and experiences internationally is outlined.

\section{Reasons for logistics outsourcing}

The literature identifies many reasons to outsource and many benefits of outsourcing, some of which are the following: cost saving; improvement of services; the ability to access outside expertise; strategic repositioning; strategic sourcing; greater service integration and/or higher value creation; a search for greater efficiency and increased specialisation; faster, cheaper and better support functions; solutions to problems created by business reorganisation and restructuring; global supply and de-integration; global competition and the need to have fewer suppliers and higher levels of service and quality from them; and contracts with fewer suppliers and closer, long-term relationships with a smaller number of providers.

A logistics service provider can add value to an organisation at a number of different levels, depending on the extent to which it is utilised and integrated into an organisation's supply chain. A 3PL can add value at the most basic execution level of the supply chain by determining and arranging for the most appropriate method of transporting a single shipment of goods, while at the most sophisticated level, a provider can be fully integrated into an organisation's supply chain. In this case, a 3PL designs, co-ordinates and executes a supply chain strategy while providing the company with value-added information to better manage core competencies.

Hugo and Badenhorst-Weiss quoting van Weele (2011:62) differentiate between tactical reasons and strategic reasons for outsourcing. 'Tactical reasons are to reduce operating and control costs, to free up internal resources, to receive an important cash infusion, to 
improve performance, and to be able to manage a function that is out of control. Strategic reasons may be to improve company focus, to maintain access to world-class capabilities, to gain access to resources that are not available internally, to accelerate re-engineering benefits, to improve customer satisfaction, and to increase flexibility and share risks.'

Langley et al. (2002) also found that the order of importance of the outsourcing reasons, and factors identified by users as impacting the industries in which they compete, can change slightly. For example, security became more of an issue after 11 September 2001.

In summary, many of the reasons for outsourcing cited in literature are related to decreased costs and increased customer services, which are often related to improving management focus, enabled by outsourcing, enhancing speed to market and increasing revenue (Burns et al., 2001; Hanna, 2009). According to Konezny and Beskow (1999) outsourcing is an important means to improving logistics efficiency overall.

In the words of Accenture research findings, 'few will deny that the benefits of outsourcing continue to outweigh the resistance to it' and 'savvy companies rely on outsourcing to save money, improve quality, increase productivity and expand the flexibility of their operations' (Hanna, 2009:1). However, outsourcing is not without its issues.

\section{Problems with logistics outsourcing}

Outsourcing is fraught with potential problems such as the following: inadequately scoped work; inadequate control systems over how certain services are delivered, which in turn may raise the company's liability exposures; hidden costs and risks; inadequate high level management support or lack thereof; poor organisational communication; cross-functional political problems; unclear expectations; uncertainties associated with the stability of the service companies; and issues of confidentiality, security, timing, and lack of flexibility (Greaver, 1999; Bendor-Samuel, 2000; Lynch, 2000).

Companies are also often understandably nervous about turning over their business to a third party. Hugo and Badenhorst-Weiss (2011:63) identify the major disadvantage that all of the above can be related to, and that is 'loss of control and skills' which is a 'result of dependence on outside parties'.

Other major concerns include the transition process, the depth of the 3PL's management team, security and safety issues, trust and price (Sopher, Lareau \& Crum, 2002). Greaver (1999) summarises the various potential problem areas into the categories of people, processes and technology. The people or human resources (HR) aspect is a particularly critical area for decision makers in the area of logistics outsourcing, as corporate cultural changes and staff disruptions play an important part in the success or otherwise of a logistics 
outsourcing initiative (Armstrong, 2001). In their logistics outsourcing study, Wilding and Juriado (2004) found that cultural incompatibility and poor communication could lead to failure of a logistics outsourcing initiative.

It is therefore important for organisations to identify their areas of concern in their outsourcing initiatives and to plan for these by following certain steps in the outsourcing process. Such steps include thorough business analysis; correctly identifying core competencies; having a clear understanding of what is to be achieved by outsourcing; developing comprehensive plans to ensure that outsourcing provides enhanced business performance; choosing the correct outsourcing providers and treating them as partners; ensuring communication and honesty throughout the process; and providing adequate training and skills to facilitate the inevitable change management required by the process (Embleton \& Wright, 1998; Kuglin, 1998; Greaver, 1999; Lankford \& Parsa, 1999; Heroux, 2001; Nell, 2001). Hugo and Badenhorst-Weiss (2011:64) concur and state that 'a structured decision process should be followed to enable the decision makers to consider effectively all of the strategic and total cost implications of outsourcing'.

\section{Managerial involvement in the outsourcing decisions}

Outsourcing is potentially complex, particularly due to the fact that logistics is integrated into other company functions such as finance, marketing, manufacturing and information technology (IT) (Konezny \& Beskow, 1999; Langley, Newton \& Allen 2000). Franzetta (1999) states that no outsourcing attempt be made without the committed participation of all senior executives, in particular the chief executive officer (CEO), chief financial officer (CFO), the chief of operations, the chief information officer, and especially the chief marketing officer. It is important to bear in mind that the decision to outsource any logistics function is a strategic initiative that requires thorough pre-planning and analysis by all functional areas within an organisation. According to Armstrong (2001), the decision to outsource is usually the result of a CEO, CFO or logistics buyer questioning the current approach. He also asserts that a consultant should be retained and given the responsibility of facilitating the decision. Simultaneously, teams involving the process owners and buyers should be formed to recommend whether logistics activities should be outsourced. Cross-functional teams should study, plan and implement outsourcing initiatives, guiding the process and selection and assessing the risks, resources, information and management skills needed to mitigate those risks (Greaver, 1999). Customers, suppliers and third parties can also play important roles as team members (LaLonde, 1998).

Furthermore, organisations should consider involving outsource consultants to help the team work effectively in the shortest time, lawyers experienced in negotiating and drawing up outsourcing contracts, accountants to analyse costs using tools such as activity-based costing, and other specialists, depending on the situation (Lynch, 2000). 
Finally, globalisation and the importance of competitive advantage have led to growing interest in logistics on the part of top management. Logistics issues such as the decision to outsource are receiving increasing attention from top management and becoming increasingly strategic in nature (Lynch, 2000). Logistics managers are participating more in the formulation of organisational competitive strategy. Organisations need good logistics systems, coupled with the inclusion of logistics in the strategic planning process if they are to attain high levels of excellence and competitive advantage domestically and globally (Stock \& Lambert, 2001). Therefore, increasingly, the final decision on outsourcing is made at the corporate level, for example by the CEO and CFO, with the transportation/logistics department, for example, playing an advisory role (Burns et al., 2001).

\section{The outsourcing agreement}

The increasing pressure on companies to cut costs and focus on keeping their core business profitable has 'emphasised the importance of good business relationships, and the strong contracts and relationships that underpin them' (O'Reilly, 2009:4). The outsourcing agreement plays an important role in these regards. The foundation of the agreement, contract and relationship must be an understanding of what is to be outsourced. In its strategic analysis, the company can develop a clear understanding and quantification of the type and the level of service currently being provided in-house, and that desired in the future, in order for the request for proposal (RFP) to be compiled, the service level agreement (SLA) drafted, the tender document issued and the provider selected. Without an accurate scoping of the required services, it is almost impossible to implement and manage a successful outsourcing relationship (Kujawa, 2004). Roeser (2001) states that many outsourcing failures can be traced back to the scope of work document. A scope of services document can be used to ensure that expectations are documented and that adjustment in scope and the impact are well documented and communicated (Boyd \& Palmer, 2002). It is important to define goals and expectations explicitly. Without measurable goals, it will be impossible to quantify current results, or to define the level of service required in the future. The outsourcing company should articulate, very clearly, what they expect of the provider (Lynch, 1999 as quoted by Seideman, 1999). In this regard, Bendor-Samuel (2000) states that few users take the time to adequately define what it is they are buying. In every outsourcing relationship, preceded by a thorough RFP process, users and providers should specify exactly what services are being bought. Often the outsourcing company has unwritten expectations of the provider to make other contributions to their business goals. For example, sometimes they expect continuous improvement where none is explicitly defined or measured (Bendor-Samuel, 2000; Lynch, 2000).

Agreeing on a fair price is usually the focus of the RFP and negotiation processes. An outsourcing company must be careful to negotiate price only once it has adequately defined and agreed service and accountability levels with the provider that will supply those services (Greaver, 1999; Bendor-Samuel, 2000). With regard to the negotiation process, Slater 
(1998) states that it would be helpful if buyers of third party services consulted their lawyers before finalising any outsourcing agreement and contract. This could also include the establishment of exit level provisions and guidelines to resolve issues or disputes (Greaver, 1999). Atkinson (2002) concurs, stating that when a company enters into a contract with a $3 \mathrm{PL}$, it is always prudent to plan an exit strategy in case one or both parties wish to end the relationship. According to Garschagen and Martin (2001) the traditional approach to implementing logistics outsourcing has been to have extensive negotiations that eventually result in a detailed contract. They argue that adopting a progressive approach to negotiation eliminates potential areas of risk in terms of outsourcing failure, namely the propensity of providers to oversell their capabilities, and of clients to withhold information if they think it will increase costs (Garschagen \& Martin, 2001).

Kasilingam (1998) asserts that potential providers for the functions to be outsourced should first be identified. The selection process thus generally begins with an initial screening of provider candidates in which their experience, level of service and financial feasibility are assessed (Sopher et al., 2002). Thereafter one or a few providers can be selected. This part of the process will include the evaluation of proposals, doing site visits, obtaining references and then combining all these analytically to shortlist the final candidates (Sopher et al., 2002). The analytical results may then be combined with experiential knowledge and judgment to select the actual providers (Lynch, 2000).

With regard to the process Greaver (1999) states that the outsourcing project team should list the criteria for a qualified provider, based on the company's reasons to outsource. Potential providers are identified and preliminary investigations are made to determine their qualifications and confirm their interest in the transaction. Their qualifications are then compared to the criteria, and a decision is made on whether they should be invited to propose. The RFP must be highly structured if the proposals are to be comparable and responsive.

Lynch (2000) concurs and states that whether the company is planning to engage in a simple transactional arrangement or work towards a partnership solution, it is important first to establish the selection criteria. He provides a comprehensive set of criteria by which to shortlist and benchmark providers (e.g. financial stability, business experience, management depth and strength, reputation with other clients, strategic direction, physical facilities and equipment, operations, information technology, quality initiatives, growth potential, chemistry and compatibility, and cost). The shortlist of candidates should be visited to further ascertain the suitability of the provider (Lynch, 2000). This is particularly important when a company is working towards a partnership solution which has its own benefits, although there are increased costs in developing closer relationships (Knemeyer, Corsi \& Murphy, 2003). Webb and Laborde (2005) are of the opinion that the success of the outsourcing arrangement is in fact greatly dependent on the relationship with the provider. 
The RFP, negotiation and contractual phases, and ongoing relationship development, of outsourcing implementation are therefore important to the success of an outsourcing arrangement.

\section{Transitioning resources and managing the relationship}

Another step that is very important to the success of outsourcing implementation, in particular with regard to the transitioning of resources, is communicating with and preparing staff members for the change. Communication, change management and training are thus critical to success. According to Bailie (2001), companies desire better service but are reluctant to invest in the very resources that will allow them to improve service. As outsourcing can be a key component of the re-engineering process within a company, it has many human resource and structural implications that must be managed carefully if the implementation of an outsourcing strategy is to be successful.

According to Harps (1998), outsourced relationships should be treated as the strategic assets that they are. Successfully outsourcing logistics requires investing sufficient resources in managing that asset. Outsourcing is not abdicating responsibility; rather, it is leveraging the specialised expertise of another company. When companies outsource, they fundamentally change their structure and the way in which they create value. When an old set of management systems and skills is removed it also has to be replaced with a new set (Harps, 1998).

Lonsdale (1999) calls the continual management of supply the neglected principle. He states that while the service provider takes over the responsibilities of the operational tasks of the outsourced activity, the outsourcing company needs to continue to monitor and seek to improve supplier performance on a continuous basis, ensuring acceptable cost and performance levels. An effective measurement process is a critical component of any business relationship and specific measures should be developed and tailored to the requirements. In order to achieve success in this aspect of managing the relationship, the critical aspects of cost, service and quality must be adequately addressed (Garschagen \& Martin, 2001). Harps (1998) adds that failure to address these issues can significantly reduce outsourcing success.

From the existing literature it can be seen that there are key aspects of the outsourcing process that need to receive attention from organisations that seek to outsource their logistics activities.

These aspects can be summarised as follows:

- Organisations need to clearly define the goals and objectives that they expect to achieve by outsourcing, and therefore identify the reasons why they are outsourcing (Weiskott, 1999). 
- Organisations need to address all key issues and potential problems (Sopher et al., 2002).

- Organisations increasingly need to leverage the expertise of executives in areas such as IT, finance, marketing and manufacturing, along with that of the logistics executives at customer companies in all stages of the $3 \mathrm{PL}$ buying and management processes (Langley et al., 2000).

- Organisations need to plan and implement the outsourcing agreement meticulously. By considering various aspects of the outsourcing decision and process cautiously and thoroughly companies will achieve greater success with 3PL. This means that companies would have to include the following actions in the critical outsourcing steps: developing an RFP and SLAs, identifying and evaluating prospective 3PL partners, and conducting site visits (Razzaque \& Sheng, 1998; Sopher et al., 2002).

- Organisations need to invest resources in communication, change management and training to improve service through outsourcing. Managing the $3 \mathrm{PL}$ relationship is crucial to the ongoing success of the outsourced logistics (Harps, 1998; Bailie, 2001).

The main aim of the research on which this article is reporting was twofold: 1) to establish the practices, in each of the above aspects, among South African manufacturers who outsource their logistics, and 2) to make recommendations for improvements, if necessary.

\section{RESEARCH STRATEGY}

\section{Research approach}

In 2003, a major outsourcing study (Kujawa, 2004) was conducted through the Department of Transport and Supply Chain Management at the University of Johannesburg. This study surveyed and investigated outsourcing in the manufacturing sector in South Africa. The study elicited considerable response and interest from the manufacturing industry as well as from the transport and logistics service sector. The follow-up survey was completed in 2009 - the findings of which are presented in this article - and was designed in a response to numerous requests to update the findings of the initial study.

The purpose of both surveys was to investigate logistics outsourcing practices and issues in the manufacturing sector in South Africa. The research covered various sources of data and methods of data collection, and included an analysis of available literature, a practical field study comprising a questionnaire, and discussions with members of industry, mostly in the form of informal interviews.

The follow-up questionnaire survey process was initially conducted among pre-identified, randomly selected companies in the South African manufacturing sector. The database was obtained from the Department of Trade and Industry (DTI) and comprised the total number of registered manufacturing companies in South Africa. The database contained approximately 48300 manufacturing entities. Based on the population total, questionnaires 
were sent out to 7500 companies randomly selected from the database. The purpose of the large sample was to obtain a perspective that would adequately represent the views of the role-players within the manufacturing sector.

A very low response rate totalling only 97 valid responses (approximately 1.3\%) was obtained from the initial mail shot. It was established that the very low response rate was due to the inadequate database. The DTI database consists of all registered manufacturing companies. Registered companies are not however obliged to update contact details or other information with the DTI and details are only updated if an entity voluntarily submits such details to the DTI. Consequently, the details of the majority of companies are outdated and a large portion of the questionnaires were returned as 'address unknown'. Many other entities have ceased trading and are now dormant, since they have not been deregistered at the DTI.

While the response rate was considered to be relatively low, the number of responses (97) was deemed appropriate for the purposes of the study. Other research into supply chains and logistics has produced significant results with relatively small samples (Bowen, Cousins, Lamming \& Faruk, 2001; Rao, 2002). Since it is generally accepted that mail surveys have a relatively low response rate (Greer, Chuchinprakarn \& Seshadri, 2000), the return rate was deemed sufficient for the study purposes. Despite this appropriateness, the researchers believed that the response rate would be better if a more appropriate database were available, particularly given the known interest in the subject in the manufacturing sector. The researchers also believed that additional responses would enhance the representativeness of the survey. Accordingly a decision was taken to expand the questionnaire survey. A new database was obtained commercially from a market survey company specialising in database collection and sales. Again, manufacturing entities were requested and the database totalled approximately 7000 unique entities. A further, smaller, mail shot was done approximately four months after the first mail shot and a more appropriate response rate of approximately $11 \%$ was achieved, totalling a further 77 usable responses.

From the results of the two follow-up questionnaire surveys the two samples appeared to be quite different with respect to size and turnover of the entity, thus providing a better representation of the total population. The reason for this appeared to be that the commercial database focused on easily identifiable manufacturing entities, rather than some of the smaller enterprises. A problem that was encountered in the research process was that the first survey consisted of a random sample selected in order to provide an appropriate overview of the manufacturing sector perspective on logistics outsourcing. The slow response rate and inappropriateness of the database made it necessary for the second survey database to be commercially obtained. This database must therefore be considered a convenience sample. In order to expand the representativeness of the sample, the results for the two surveys were collated. 


\section{Participants and respondents}

These questionnaire surveys elicited a total of 174 valid responses, a number significantly large enough to draw reasonable conclusions although not necessarily large enough to extrapolate across the population. The largest percentage of respondents came from the category of manufacturers of consumer goods, and specifically finished goods. With respect to size of the respondents, measured in terms of number of employees and turnover, over $70 \%$ were small to medium (turnover of up to R100 million per annum and maximum 200 employees), while the rest were medium to large (turnover of over R100 million per annum and more than 500 employees).

\section{Measuring instrument(s) and methods of data gathering}

Based largely on the literature reviewed and similar studies undertaken internationally, an understanding was gained of the importance of logistics in companies and of the outsourcing decision. The benefits, problems and methodologies as well as the nature, specific characteristics and practicalities of logistics outsourcing were investigated. The propositions thus derived from the literature were tested against actual data gathered, mainly from the survey of logistics outsourcing, to provide and test the South African manufacturing perspective of logistics outsourcing. The design of the initial survey and sample was undertaken in close consultation with Statkon, which is a statistical consultation service at the University of Johannesburg.

The dimensions of the questionnaire covered but were not limited to determining the reasons that manufacturers outsourced their logistics, problems they encountered, and their practices with regard to outsourcing initiatives.

\section{Qualifier: Definition of logistics service provider}

No differentiation was made in the survey between logistics service providers, third party logistics service providers, and fourth party logistics service providers. All questions in this regard merely referred to logistics service providers, and the following definition was provided to clarify what was meant by logistics outsourcing: Logistics outsourcing is 'an arrangement whereby a logistics service provider performs services for a firm that could be, or have been, provided in-house, i.e. the firm subcontracts logistics activities to providers equipped to perform these services' (Lynch, 2000:2).

\section{Statistical analysis and treatment of the data}

Statkon undertook the statistical analysis of the survey results, and provided assistance with regard to the descriptive and graphical data analysis and interpretation of the results, affording comment on the written findings of the survey once they were in report format, thus helping to ensure that the statistical content of the research was valid. 
Statkon undertook the initial data analysis of the completed questionnaires, providing frequencies for all questions asked. These results provided the basis for the description of the participants' responses with regard to logistics outsourcing in terms of reasons to outsource and not to outsource, levels of outsourcing, levels of satisfaction or success, issues or problems, and general practices, expectations and opinions. Statkon then undertook further data analysis requested in order to identify important links between certain variables. These results are discussed in the following section.

\section{Shortcomings of the research and literature}

The response rate to the follow-up survey was unfortunately low and makes it difficult to draw firm conclusions. The database used for the 2003 survey was no longer available when the follow-up survey was undertaken and the database that had to be used was inadequate in comparison. It was also decided not to specifically refer in this article to the results of the 2003 survey and rather to address a detailed comparison, although the surveyed databases differ, between the 2003 results and those of the follow-up survey in a separate article. This will be undertaken once a further follow-up survey has been completed, which has already been planned and which will provide more data for the purposes of comparison. The shortcomings of this research regarding the database, response rate and representativeness of the survey will be addressed accordingly. Nevertheless, as mentioned, the number of responses was still deemed appropriate for the purposes of the study and the results thereof are presented below

\section{RESULTS AND DISCUSSION}

As mentioned previously, it is critical for an outsourcing company to identify the benefits sought and reasons for undertaking such an initiative, the potential problems to be avoided, and the important steps that should be identified, planned for and followed in the outsourcing process. In light of the importance of these various aspects in a logistics outsourcing initiative, significant practices and issues were highlighted by the statistical analysis of the data gathered during the above-mentioned research.

\section{Reasons to outsource}

With regard to the expected benefits and listed reasons for their outsourcing, 77\% of the respondents indicated that they outsourced logistics to a large or moderate extent due to a focus on core competencies, $76 \%$ due to geographical coverage, $73 \%$ outsourced logistics to a large or moderate extent due to the pressure to improve customer service, $57 \%$ due to market expansion, $56 \%$ due to the pressure to cut costs, $49 \%$ due to a lack of internal expertise and capability, and $25 \%$ due to BEE and labour relations considerations.

This indicates that the majority of respondents were under pressure to focus on core competencies and for reasons of geographical coverage. The majority of respondent 
organisations were also under pressure to improve customer service, expand markets and cut costs.

\section{Areas of concern with outsourcing}

Areas of concern that were raised most frequently to a moderate and large extent were that service level commitments were not realised, as stated by $51 \%$ of the respondents. There were also cost creep and price increases after the relationship started (47\%) and cost reductions were not realised (45\%). Furthermore, 38\% felt that the time and effort which they spent on logistics had not been reduced.

Other issues, raised by less than $35 \%$ of the respondents, included the following: control over the outsourced function being diminished, technology capabilities not being delivered, lack of strategic management skills, lack of continuous ongoing improvement in service, lack of consultative knowledge-based skills, and misunderstandings or disagreements with providers.

\section{Managerial involvement}

In this process of outsourcing, and these steps undertaken, it was found that certain managers and areas of management were included to some extent (large, moderate or small extent) while others were not. It had been hoped that management representation from all of these areas would be involved in any outsourcing project. As expected the majority of respondents noted that the logistics/distribution (90\%), finance (82\%), manufacturing (71\%), procurement/purchasing (69\%), and marketing (61\%) managers or functions were involved in the process. However, only $42 \%$ of the respondents involved managers from the information technology function, $36 \%$ managers from the legal function, and $28 \%$ managers from human resources. These findings are summarised in Figure 1.

\section{\% OF COMPANIES WHICH INVOLVED:}

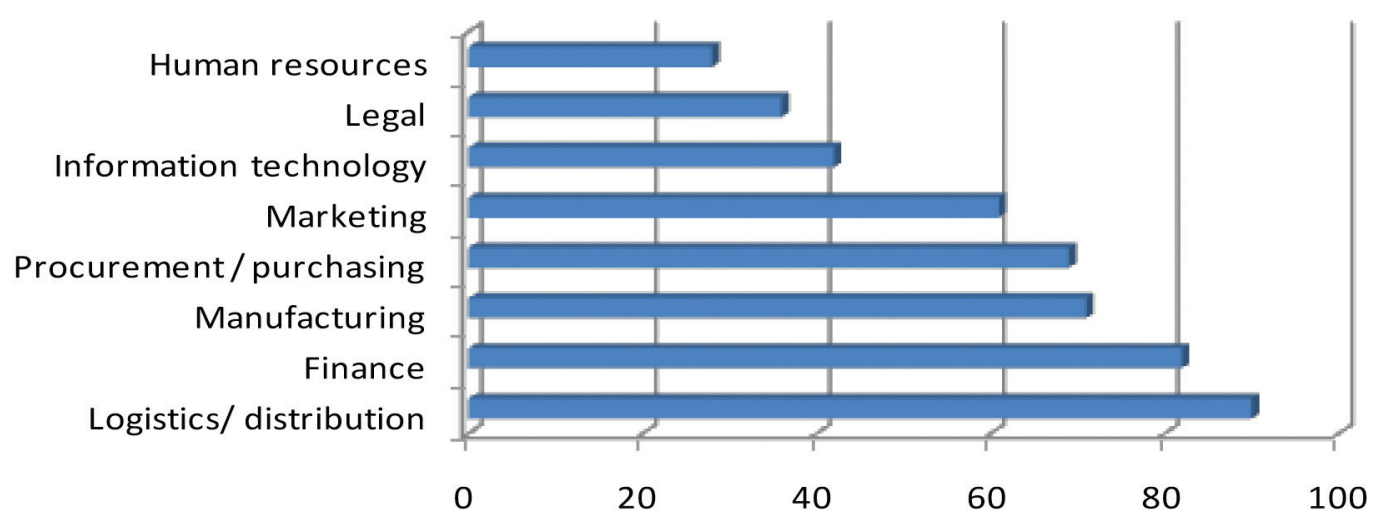

Figure 1: Managerial involvement by respondent companies 


\section{The outsourcing agreement}

With regard to time spent on steps that are important in establishing an outsourcing agreement that will address typical problems and areas of concern, it was found that over three-quarters of the respondents focused on analysing current costs and performance (85\%) and negotiating terms of the contract (79\%). Over half spent time on exploring the strategic implications (71\%), developing service level agreements (63\%), determining security arrangements (59\%) and checking references on the provider (57\%).

To a lesser extent the organisations also spent time on developing guidelines to resolve issues or disputes (47\%), compiling the request for proposal (42\%), visiting the providers' sites (41\%) and developing exit provisions (37\%).

These various responses are reflected in Figure 2.

\section{\% OF COMPANIES WHO SPENT TIME ON:}

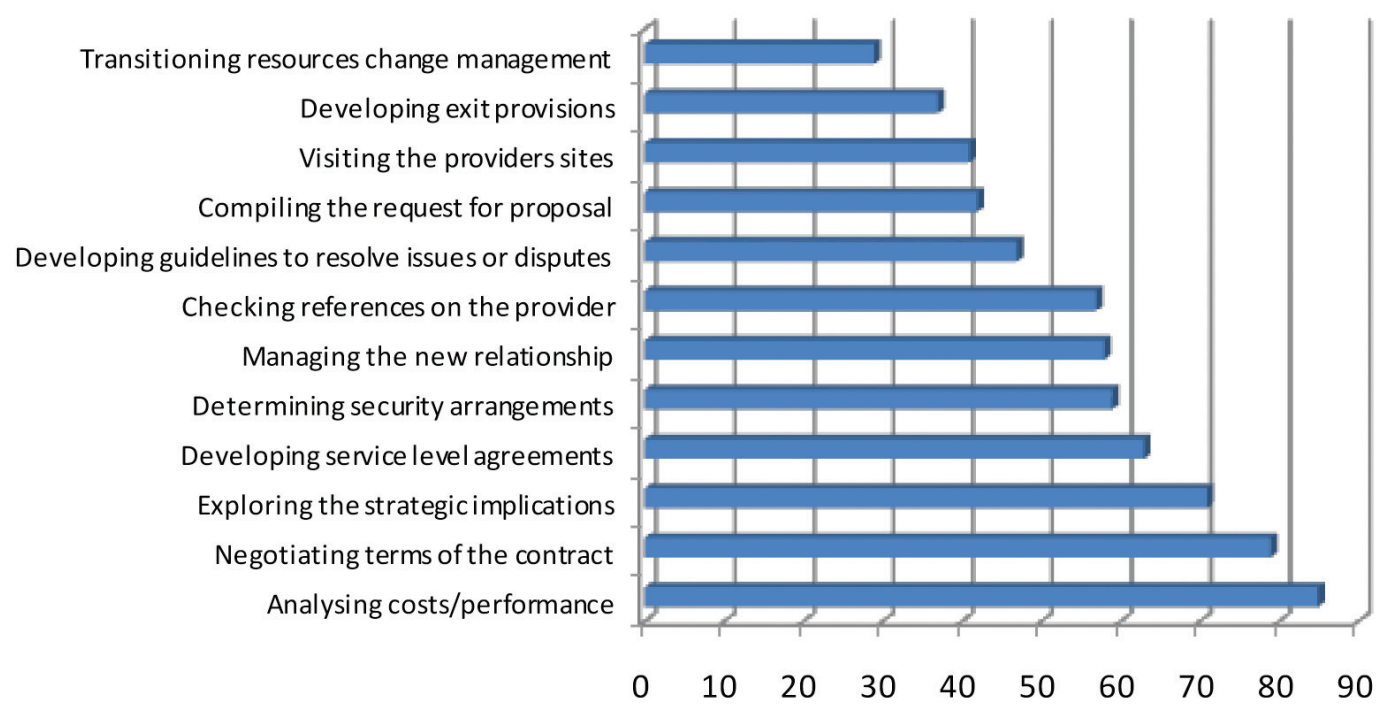

Figure 2: Time spent on outsourcing steps by respondent companies

\section{Transitioning resources and managing the relationship}

As can also be seen in Figure 2, with regard to time spent on ongoing aspects of outsourcing that are important for satisfaction in outsourcing, it was found that, to a moderate or large extent, organisations focused on managing the new relationship (58\%), while to a lesser extent, the organisations also spent time on transitioning resources and change management (29\%).

\section{Managerial implications of findings and recommendations Reasons for outsourcing}

A lack of clearly defined reasons for outsourcing can not only impact the benefits to be realised in an outsourcing initiative but can also affect the potential problems experienced 
in the process. One of the most frequent complaints from providers is that potential customers often do not know the reasons why they are outsourcing logistics or do not fully understand their own in-house logistics or logistics requirements (Weiskott, 1999).

Although it was not clear from the research whether South African manufacturing organisations adequately defined their goals and objectives prior to outsourcing, the findings did show that when selecting outsourcing reasons from a given list, the organisations generally outsourced logistics activities with the intention of focusing on their core competencies, due to geographical coverage and pressure to improve customer service. Although the majority also outsourced logistics for market expansion, which would tie in with the geographical coverage requirements and reasons, only half of the respondents felt that they had a lack of internal expertise and capability. It is also a matter of concern that only a small majority seemed to outsource to reduce costs. Cost reduction is identified by the literature and organisational experience internationally as a key benefit and reason for logistics outsourcing.

It is recommended that these South African organisations clearly identify and analyse their current logistics requirements and identify their requirements in this regard. When considering the option of outsourcing for these logistics requirements they could then clearly identify the reasons why they will be undertaking the outsourcing, such as service level improvements or cost reductions. Once they have clarified these reasons they will be better equipped to proceed with the outsourcing process such as selecting the right provider for their requirements.

\section{Issues and problems}

Various problems and issues of outsourcing often arise due to poor outsourcing decisions and management. Furthermore, outsourcing problem areas can have their root causes in either party, and addressing the problems is a shared responsibility between user and provider (Greaver, 1999). Ensuring the success of an outsourcing project must therefore include the identification and management of potential problems, since the more planning undertaken around the risk factors before implementation, the higher the probability of success. Developing a comprehensive plan outlining detailed expectations, requirements and expected benefits is crucial (Elmuti \& Kathawala, 2000; Lonsdale \& Cox, 2000).

The majority of respondent organisations in the South African survey had concerns about cost reduction and service level commitments. Many also felt that time and effort spent on logistics was not reduced. Further concerns related to reduced control over the outsourced function and lack of service delivery by the provider with respect to technology, management skills, ongoing improvement and knowledge. Misunderstandings and disagreements were also a problem for some. 
It is recommended that these South African organisations clearly define their requirements in terms of costs and service delivery in the RFP and SLAs. These aspects should be thoroughly negotiated and clearly reflected in the contract to avoid misunderstandings. The ongoing management of the outsourced relationship and clear and effective communication channels will also assist in reducing misunderstandings and disagreements with the provider.

\section{Managerial involvement}

The real benefits of logistics outsourcing will be reduced unless the broad spectrum of managers, who will ultimately be impacted by the outsourcing decision, are given the chance to express their interests and concerns, and have an input in the decision-making and outsourcing process (Franzetta, 1999). The outsourcing project should also include organisational support overall, and the support of top management specifically.

With regard to managerial involvement the respondents in the South African survey indicated that, although the logistics/distribution, finance, manufacturing, procurement/ purchasing and marketing functions were generally involved in the outsourcing process, the $I T$, legal and HR departments were generally not.

It is recommended that these South African organisations identify and take into consideration their various organisational functions that will be impacted by the logistics outsourcing. These functional managers should be involved in the outsourcing decision-making and implementation process in the form of project teams and in a consultative manner. Where necessary these managers could also be included in the ongoing management of the outsourced relationship.

\section{Outsourcing agreement}

Preceding discussions regarding the critical steps in the outsourcing process, in order to negate potential problems and promote success, can be concluded with the following basic rules for successful logistics outsourcing: develop a strategy for outsourcing; establish a rigorous provider selection process; clearly define your expectations; develop a good contract; establish sound policies and procedures; identify and avoid potential friction points; communicate effectively with logistics partners; measure performance and communicate results; motivate and reward partners; and be a good partner (Lynch, 2001). 
In the South African survey it was found that organisations typically spent time on analysing their current costs and performance, negotiating terms of the contract, exploring the strategic implications, developing service level agreements, determining security arrangements, and checking references on the provider.

However, it is recommended that all organisations embarking on logistics outsourcing consider the importance of these steps in terms of understanding the organisation's current logistical operations and the strategic implications of logistics outsourcing. The importance of stipulating performance and cost expectations in terms of a good contract, policies, procedures and SLAs should be clearly understood by all organisations. It is furthermore recommended that, in addition to this strategic planning, negotiating and contracting, these organisations also select the right provider and continue in a partnership-type arrangement with the provider. Finally, in this regard, it is recommended that South African organisations that outsource their logistics pay more attention to developing guidelines to resolve issues or disputes, compiling RFPs, visiting the provider sites and developing exit provisions.

\section{Transitioning resources and managing the relationship}

While every effort should be made to ensure that the best possible provider is selected, the transitioning of resources and managing of the new relationship and agreement can have a key impact on the success of the outsourcing initiative. If relationships with logistics providers are managed well, costs can be reduced while service and customer satisfaction are improved (Harps, 1998).

With regard to the above-mentioned aspects of logistics outsourcing in South Africa, the responding organisations appear to be managing the new relationship well. However, less than one-third of the organisations spent time on transitioning resources and change management.

It is therefore also recommended that far greater consideration be given to the impact of resource and relationship management on successful outsourcing and ongoing success in the relationship with the provider. Organisations should also select providers that have good change management and communication practices to ease the transition to outsourcing and ensure ongoing improvements in their operations in the long term. 


\section{CONCLUSION}

The preceding discussions in this article reveal that although outsourcing is not a solution for all logistics problems in a company, if properly planned, executed and monitored, it can contribute to an organisation's ability to control costs, improve customer service and allow the company to focus on its core competencies.

The aim of this article has been to investigate various logistics outsourcing practices as identified in international literature, to ascertain some of the practices of South African manufacturing companies with respect to these aspects of logistics outsourcing, and to make recommendations to these organisations.

This literature review and survey of South African manufacturing organisations shows the benefits that can be achieved through logistics outsourcing and highlights how important it is for an organisation to clearly define its reasons for outsourcing. It also points out the potential problems with outsourcing and the need for organisations to identify and recognise the problems and deal with them accordingly, and emphasises the necessity of including the managers of all affected areas in the process. It is evident that logistics outsourcing is increasingly viewed as a strategic initiative with far-reaching consequences, and that it requires careful consideration and a thorough process to improve the chances of success. For example, when developing the outsourcing agreement the outsourcing company should clearly define its requirements in terms of the RFP and specifically select a provider for those requirements. The negotiating and contracting of terms, provisions and guidelines should receive adequate attention. The better the outsourcing process is planned and the more effectively time is spent on planning, the higher the probability of success. Finally, it is important to see the logistics service provider or 3PL as a partner in the organisation's logistics and to dedicate the necessary resources in the transition and the ongoing management of the relationship.

From the findings of the research into logistics outsourcing practices of manufacturers in South Africa, it appears that the most prominent issues with regard to the reasons for outsourcing are currently that the majority of the organisations are under pressure to focus on core competencies and to cover expanded geographic markets. Organisations are also under pressure to improve customer service and reduce costs. They do however have problems in their logistics outsourcing with service levels not being met and costs increasing, once they have contracted with a 3PL. It was found that the majority of the organisations involve their logistics, finance, manufacturing, procurement and marketing functions in the outsourcing and it is recommended that manufacturers also involve their IT, HR and legal functions. With regard to the outsourcing agreement and relationship, although many organisations do follow the identified important steps, it is recommended 
that all organisations focus more on analysing current costs and performance, negotiating terms of the contract, exploring the strategic implications, developing SLAs, determining security arrangements, checking references on the provider, developing guidelines to resolve issues or disputes, compiling the RFP, visiting the provider sites, developing exit provisions, managing the new relationship and transitioning resources, and managing change.

These various findings and recommendations have been summarised in Table 1 to underpin the suggested improvements for organisations embarking on a logistics outsourcing initiative.

Table 1: Summary of findings and recommendations

\begin{tabular}{|c|c|}
\hline Findings & Recommendations \\
\hline $\begin{array}{l}\text { Reasons to outsource are mostly to: } \\
\text { - Focus on core competencies } \\
\text { - Cover expanded geographic markets } \\
\text { - Improve customer service } \\
\text { - Reduce costs }\end{array}$ & Define reasons for outsourcing clearly \\
\hline $\begin{array}{l}\text { Problems are mostly related to: } \\
\text { - Service levels are not met } \\
\text { - Costs increase }\end{array}$ & Identify issues and plan for problems \\
\hline $\begin{array}{l}\text { Functions mostly included are: } \\
\text { - Logistics } \\
\text { - Finance } \\
\text { - Manufacturing } \\
\text { - Procurement } \\
\text { - Marketing }\end{array}$ & $\begin{array}{l}\text { Include managers of all affected areas } \\
\text { including IT, HR, legal }\end{array}$ \\
\hline $\begin{array}{l}\text { Many organisations follow the identified } \\
\text { outsourcing steps the most important being: } \\
\text { - } \quad \text { Analyse current costs and performance } \\
\text { - Negotiate terms of the contract } \\
\text { - Explore strategic implications } \\
\text { - Develop SLAs } \\
\text { - Determine security arrangements } \\
\text { - Check references on the provider } \\
\text { - Develop guidelines to resolve issues } \\
\text { - Compile the RFP } \\
\text { - Visit the provider sites } \\
\text { - Develop exit provisions } \\
\text { - Manage the new relationship } \\
\text { - Transition resources } \\
\text { - Manage change }\end{array}$ & $\begin{array}{l}\text { Consider the whole process thoroughly } \\
\text { especially the outsourcing agreement and } \\
\text { relationship } \\
\text { Follow ALL of the identified important steps } \\
\text { Recognise the } 3 \mathrm{PL} \text { as a partner } \\
\text { Dedicate the resources for the transition } \\
\text { Manage the relationship }\end{array}$ \\
\hline
\end{tabular}

As outlined in the introduction of this article, organisations in South Africa would benefit from improved logistics practices. Considering the country's export-led growth strategy, this would make products more competitive especially over the long distances that exist between the country and its trading partners. As South Africa becomes increasingly involved 
in the global economy, local manufacturers are being exposed to increasing pressure to be more competitive. Manufacturers, thus driven by the need to conform to world standards and contain costs, can consider the outsourcing of their logistics requirements. However, in order to reap the potential benefits of logistics efficiency through outsourcing, it is critical that the process is executed properly and with diligence (Kujawa, 2004).

In conclusion, as stated by two of the outsourcing experts, Greaver (1999) and Lynch (2000), it takes time to implement an outsourcing initiative, and even longer to do it right. Although it is tedious and difficult to undertake the logistics outsourcing processes diligently and thoroughly, it will position an organisation anywhere in the world to achieve the competitive advantage so elusive in today's dynamic and challenging marketplace. 


\section{REFERENCES}

Armstrong, R.D. 2001.3PL Trends: Growth after a slow 2001. Available from: www.3PLogistics. com or dick@3PLogistics.com (Accessed 20 February 2002).

Atkinson, H. 2002. Get a pre-nuptial agreement: Technology can be a problem if a logistics outsourcing contract doesn't work out. JoC Week. 18 February 2002 3(7). Available from: http://infotrac.london.galegroup.com/itw/infomark/258/473/21702571w4/purl=rc1_GBI. (Accessed 14 March 2002).

Bailie, M. 2001. It's a 'screwed up' world. Logistics News. March 2001:9.

Bendor-Samuel, P. 2000. Turning lead into gold: The demystification of outsourcing. Provo, UT: Executive Excellence Publishing.

Bowen, F., Cousins, P., Lamming, R. \& Faruk, A. 2001. The role of supply management capabilities in green supply. Production and Operations Management. 10(2):174-89.

Boyd, S. \& Palmer, C. 2002. Implementing a third party logistics solution - A step-by-step process. CLM Annual Conference Proceedings, October 2002.

Burns, G.E., Warren, C.K. \& Cook, B.P. 2001. Industry update: Transportation outsourcing survey: Emerging trends in logistics. JP Morgan Securities Inc. Equity Research. August 2001. New York.

Chow, G. \& Gritta, R. 2002. The growth and development of the US third party logistics industry. Supply Chain and Logistics Canada. Available from: http://www.infochain.org/ quarterly/Sp02/Chow.html (Accessed 9 June 2003).

Elmuti, D. \& Kathawala, Y. 2000. The effects of global outsourcing strategies on participants' attitudes and organisational effectiveness. International Journal of Manpower. 21(2). Available from: http://barbarina.emeraldinsight.com $/ \mathrm{vl}=44820841 / \mathrm{cl}=24 / \mathrm{nw}=1 / \mathrm{rpsv} / \mathrm{cw} /$ mcb/01437720/v21n2/s3/p112.html (Accessed 25 March 2002).

Embleton, P.R. \&Wright, P.C. 1998. A practical guide to successful outsourcing. Empowerment in Organisations, 6(3). Available from: http://barbarina.emeraldinsight.com/vl=61233134/ $\mathrm{cl}=22 / \mathrm{nw}=1 / \mathrm{rpsv} / \mathrm{cw} / \mathrm{mcb} / 09684891 / \mathrm{v} 6 \mathrm{n} 3 / \mathrm{s} 3 / \mathrm{p} 94 . h t m l$ (Accessed 25 March 2002).

Franzetta, C. 1999. Outsourcing without frustration. Inbound Logistics. January 1999:42. 
Garschagen, C. \& Martin, B. 2001. Logistics outsourcing - A leopard can change its spots. Dawson Dialogue, Dawson Consulting, a Dawson Group Company. Available from: www. dawsonconsulting.com.au (Accessed 9 June 2003).

Greaver II, M.F. 1999. Strategic outsourcing. New York: AMA Publications.

Greer, Chuchinprakarn \& Seshadri 2000. Likelihood of participating in mail survey research. Industrial Marketing Management. 29(2):97-109.

Hanna, B. 2009. Getting the most from outsourcing. Accenture Research Insights. Available from: http://www.accenture.com/Countries/Canada/Research_And_Insights/ GettingOutsourcing... (Accessed 12 July 2009).

Harps, L.H. 1998. Partnering for performance, Inbound Logistics, July 1998: 26-40.

Heroux, R. 2001. Moving from third party logistics (3PL) to fourth party logistics (4PL). Logistics News. April 2001:16.

Hugo, W.M.J. \& Badenhorst-Weiss, J.A. 2011. Purchasing and supply management. Sixth edition. Pretoria: Van Schaik.

Kasilingam, R.G. 1998. Logistics and transportation: Design and planning. Dordrecht: Kluwer Academic Publishers.

Knemeyer, A.M., Corsi, T.M. \& Murphy, P.R. 2003. Logistics outsourcing relationships: Customer perspectives. Journal of Business Logistics. Spring 2003:77-109.

Konezny, G.P. \& Beskow, M.J. 1999. Third-Party Logistics: Improving global supply chain performance. Piper Jaffray Equity Research: Third-Party Logistics. January 1999.

Kuglin, F.A. 1998. Customer-centred supply chain management. New York: Amacon.

Kujawa, B.J. 2004. An investigation into logistics outsourcing practices, trends and issues. Unpublished doctoral thesis. Johannesburg: Rand Afrikaans University (now University of Johannesburg).

LaLonde, B.J. 1998. Insights: Building a supply chain relationship. Supply Chain Management Review. Fall 1998:7-8. 
Langley, C.J., Allen, G.R. \& Tyndall, G.R. 2002. 3PL Results and findings of the 2002 Seventh Annual Study. Georgia Institute of Technology, Cap Gemini Ernest \& Young, and Ryder System, Inc. 2002.

Langley, C.J., Newton, B. \& Allen, G.R. 2000. Third-Party Logistics Services: Views from the customers: Results and findings of the 2000 Fifth Annual Study. University of Tennessee, Exel, and Cap Gemini Ernest \& Young. 2000.

Lankford, W.M. \& Parsa, F. 1999. Outsourcing: A primer. Management Decision, 37(4). Available from: http://barbarina.emeraldinsight.com/vl=44820841/cl=24/nw=1/rpsv/cw/ mcb/00251747/v37n4/s1/p310.html (Accessed 25 March 2002).

Lonsdale, C. 1999. Effectively managing vertical supply relationships: A risk management model for outsourcing. Supply Chain Management: An International Journal. 4(4). Available from: http://alidoro.emeraldinsight.com/vl=3005954/cl=30/nw=1/rpsv/cw/ mcb/13598546/v4n4/s2/p176.html (Accessed 25 March 2002).

Lonsdale, C. \& Cox, A. 2000. The historical development of outsourcing: The latest fad? Industrial Management and Data Systems. 100(9). Available from: http://cherubino. emeraldinsight.com/vl=4110871/cl=34/nw=1/rpsv/cw/mcb/02635577/v100n9/s5/p444. html (Accessed 25 March 2002).

Lynch, C.F. 2000. Logistics outsourcing - A management guide. Oak Brook: Council of Logistics Management.

Lynch, C.F. 2001. Basic rules of logistics outsourcing, The 28th Supply Chain Management Executive Development Seminar, 15 February 2001. Available from: http://www.louisville. edu/org/lodi (Accessed 1 February 2002).

Nell, F. 2001. Know your costs. Logistics News. March 2001:9.

O'Reilly, K. 2009. 3PL Selection and contracts renewal. Conference proceedings of the 7th European 3PL Summit held in Brussels, Belgium.

Rao, P. 2002. Greening the supply chain, a new initiative in South East Asia. Journal of Operations and Production Management. 22(6):632-55.

Ravi, R. 2001. eLogistics: Key trends in the logistics outsourcing marketplace. IDC - Bulletin. 24119(1), March 2001. 
Razzaque, M.A. \& Sheng, C.C. 1998. Outsourcing of logistics functions: A literature survey. International Journal of Physical Distribution and Logistics Management. 28(2):89-107.

Roeser, J. 2001. On the issue of why logistics outsourcing fails. Logistics-aug.com. 2001:1-4.

Seideman, T. 1999. To get what you want - Know what you need. Inbound Logistics. January 1999:110-18.

Slater, A. 1998. Standard Form Contracts: Specimen Contract from Added Value Logistics Consulting Ltd, April 1998.

Sopher, S., Lareau, M. \& Crum, M. 2002. Third-party logistics outsourcing. Deloitte \& Touche's Transportation Trends. 4(1), Winter 2002.

Stock, J.R. \& Lambert, D.M. 2001. Strategic logistics management. Fourth edition. Boston: McGraw-Hill International Editions.

Webb, L. \& Laborde, J. 2005. Crafting a successful outsourcing vendor/client relationship. Business Process Management Journal. 11(5):437-43.

Weiskott, M.N. 1999. Logistics outsourcing - Third-party providers can cut costs, Plants Sites and Parks Magazine, February/March 1999. Available from: http://www.bizsites.com/1999/ FM99/distribution.html (Accessed 9 June 2003).

Wilding, R. \& Juriado, R. 2004. Customer perceptions on logistics outsourcing in the European consumer goods industry. International Journal of Physical Distribution and Logistics Management. 34(8):628-44.

\section{Table of acronyms}

\begin{tabular}{|l|l|}
\hline 3PL & Third Party Logistics Provider \\
\hline BEE & Black Economic Empowerment \\
\hline CEO & Chief Executive Officer \\
\hline CFO & Chief Financial Officer \\
\hline DTI & Department of Trade and Industry \\
\hline HR & Human Resources \\
\hline RFP & Request for Proposal \\
\hline SLA & Service Level Agreement \\
\hline
\end{tabular}

